Case Report

\title{
Malignant Solitary Fibrous Tumor of the Kidney: Report of the First Case Managed with Interferon
}

\author{
Javier Cuello ${ }^{1,2}$ and Ricardo Brugés ${ }^{1}$ \\ ${ }^{1}$ Clinical Oncology Group, Cancerology National Institute, E.S.E., Bogota, Colombia \\ ${ }^{2}$ El Bosque University, Bogota, Colombia
}

Correspondence should be addressed to Javier Cuello; jamacl@hotmail.com

Received 10 November 2012; Accepted 9 December 2012

Academic Editors: J. M. Buchanich, D. V. Jones, and D. Yin

Copyright (c) 2013 J. Cuello and R. Brugés. This is an open access article distributed under the Creative Commons Attribution License, which permits unrestricted use, distribution, and reproduction in any medium, provided the original work is properly cited.

\begin{abstract}
Solitary fibrous tumors of the kidney are extremely rare tumors with unpredictable behavior. We describe a case of a patient with a solitary fibrous tumor of kidney with malignant findings with distant metastasis and nephrectomy managed with subcutaneous interferon achieving 23 months of progression-free survival. To date there is no prospective evaluation of any specific modality of treatment, but the surgical management and long-term followup are the only ones so far recommended strategies in the management of these patients. Studies are awaited with more patients to evaluate the different strategies of systemic therapy reported so far to allow adding survival benefit.
\end{abstract}

\section{Introduction}

Solitary fibrous tumors are rare mesenchymal neoplasms, considered a variant of hemangiopericytomas usually originates in the pleura; however, there have been reports of extrapleural origin (abdomen, retroperitoneum, upper extremities, orbit, cervix, meninges, mediastinum, parotid, nasal cavity, neck, etc.) [1-4]. The location is even more rare urogenital, and according to the literature, only 49 cases of solitary fibrous tumor of the kidney have been reported in the literature [5]. The origin of the majority of cases formed in the kidney is found in the renal capsule tissue or connective tissue interstitial peripelvis. Most cases presented with suspected renal cell neoplasms; however, morphologically, solitary fibrous tumors are characterized by the proliferation of spindle cells with little pattern in their architecture, and the final diagnosis was made with immunohistochemical findings that show staining for CD34 [6-9].

\section{Case Report}

A 49 year old woman with no history of importance who enters the emergency room by 2-months of dyspnea at rest, associated with pleuritic chest pain on right chest, dry cough, no fever. The chest radiograph showed a right pleural effusion and multiple nodular lesions on the pleura, so we decided to perform a CT chest and abdomen in which evidenced free right pleural effusion occupying $80 \%$ of the right chest, at least two pleural masses with solid density that capture the contrast, multiple pulmonary nodules with soft tissue density in both lungs and left kidney mass. Carried left nephrectomy with suspected metastatic renal carcinoma, shows renal mass plus liver metastases which were resected. The analysis of the tumor presented as a first option versus solitary fibrous tumor angiomyolipoma. Immunohistochemical studies that showed cell reactivity with CD34, CD99, BCL-2, and vimentin are negative for HMB-45, AMS, CD68, cytokeratin cocktail, and S100, and the Ki67 is not assessable (Figure 1). This profile supports the histological diagnosis of solitary fibrous tumor with origin in the kidney.

We decided to start treatment with interferon a2b subcutaneous dose, extrapolating the cases of patients with solitary fibrous tumor of the pleura [12]. The dose was adjusted for flu symptoms and she is with stable disease at 23 months follow-up. 

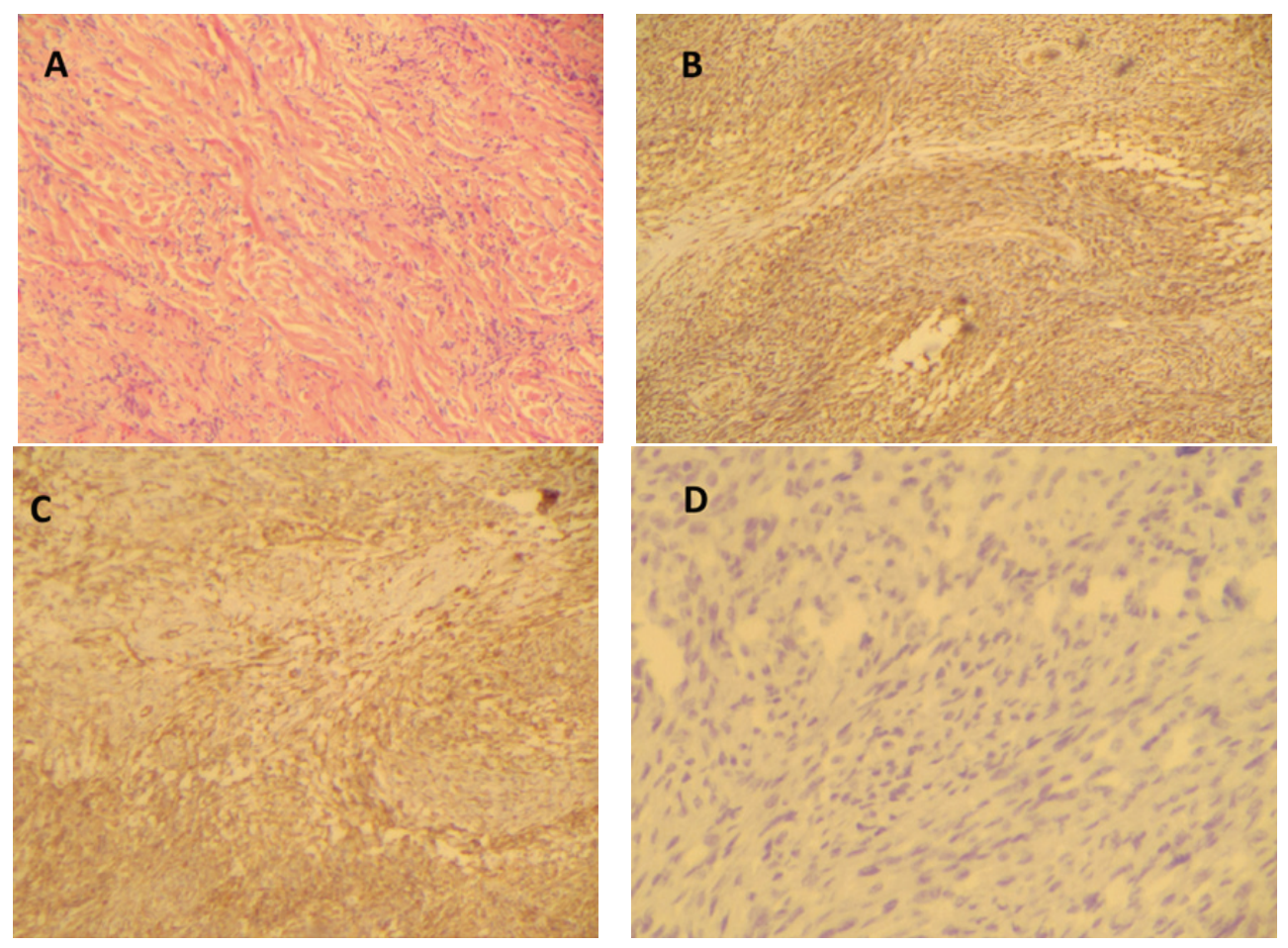

FIGURE 1: Immunohistochemical evidence CD34 positive cells (panel B), vimentin (panel C), and negative for S100 (panel D).

\section{Discussion}

Solitary fibrous tumors are extremely rare tumors, arising mostly at the level of the pleura, and cases arising from the urogenital region are even more rare, with 49 cases reported so far in the literature. The histogenesis of this entity is still unknown, but recent studies suggest a primitive mesenchymal cells or level perivascular $[10,11]$.

The differential diagnosis of these cases includes sarcomatoid variant of renal carcinoma, angiomyolipoma, fibromas, and fibrosarcomas. Table 1 presents the cases so far published, reporting the primary source, and histologic variant outcomes.

These results show a relatively rare entity, with peak presentation in the fifth decade of life, arising mostly in the renal parenchyma unilaterally (Table 2 ).

About $14 \%$ of patients have aggressive behavior where common management strategy is nephrectomy with complete resection of the lesions. The pathological findings that have been correlated with aggressive behavior are pleomorphism, increased cellularity and mitotic activity ( $>4$ mitosis/10 high-power fields), necrosis, hemorrhage, and atypical sites (parietal pleura, lung parenchyma) [13]. However, even the clinical behavior can not accurately predict the histopathological findings, as some cases with results suggesting benign disease may show aggressive behavior and vice versa, so it is necessary that these patients have an indefinite period of observation [14-19].

In relation to the management of this condition, there is as yet no prospective evaluation of any specific treatment modality; however, case reports and retrospective case series suggest that complete surgical resection and long-term followup are generally most recommended strategies. In cases such as the present, which present with metastatic disease, there is no clearly defined systemic therapy. Metastasectomy is thought to improve progression-free survival, but in many cases like this, this strategy is not feasible.

In case reports hemangiopericytomas, entity closely related to solitary fibrous tumors, has achieved stable disease with the use of interferon with or without thalidomide. So far, this is the first case reported in the literature in which benefit is demonstrated with the use of interferon in a patient with a malignant variant renal solitary fibrous tumor with metastatic disease, achieving stable disease for about 20 months.

Some authors suggest the use of antiangiogenic therapies (bevacizumab, sunitinib, pazopanib, etc.), based on the findings of high vascularity and a possible origin of pericytes at this entity [15]. The combination of bevacizumab associated with temozolomide is a potentially promising scheme for patients with solitary fibrous tumors. A series of 14 patients with solitary fibrous tumor unresectable or metastatic, were treated with temozolomide $150 \mathrm{mg} / \mathrm{m} 2$ orally on days 1-7 and days 15-21 and bevacizumab $5 \mathrm{mg} / \mathrm{kg}$ intravenously on days 8 and 22, with cycles every 28 days. In this study, 11 patients (79\%) achieved partial response assessed by Choi criteria with 2 cases (14\%) with stable disease. The median progression-free survival was 8.6 months $[12,19,20]$. 


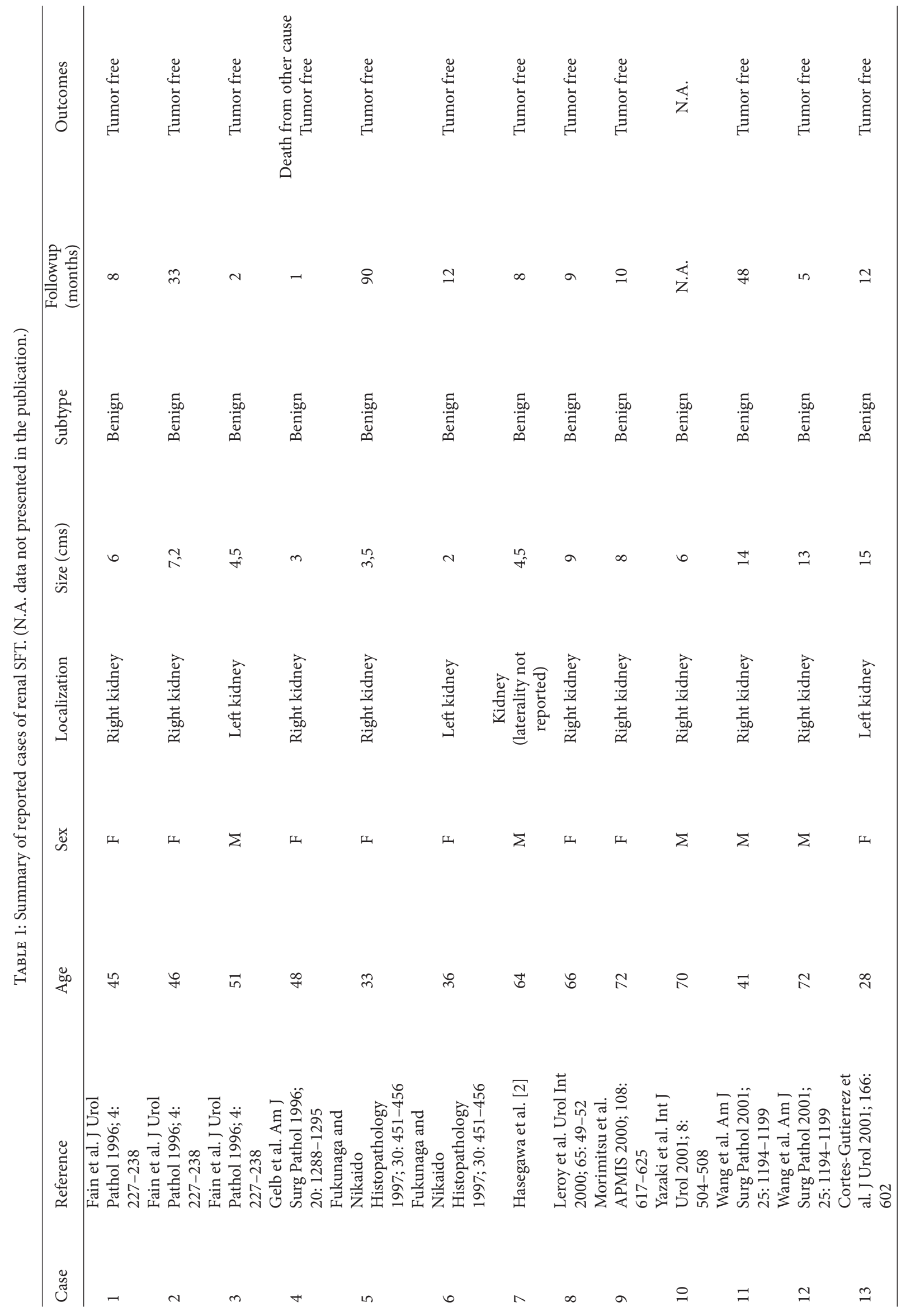




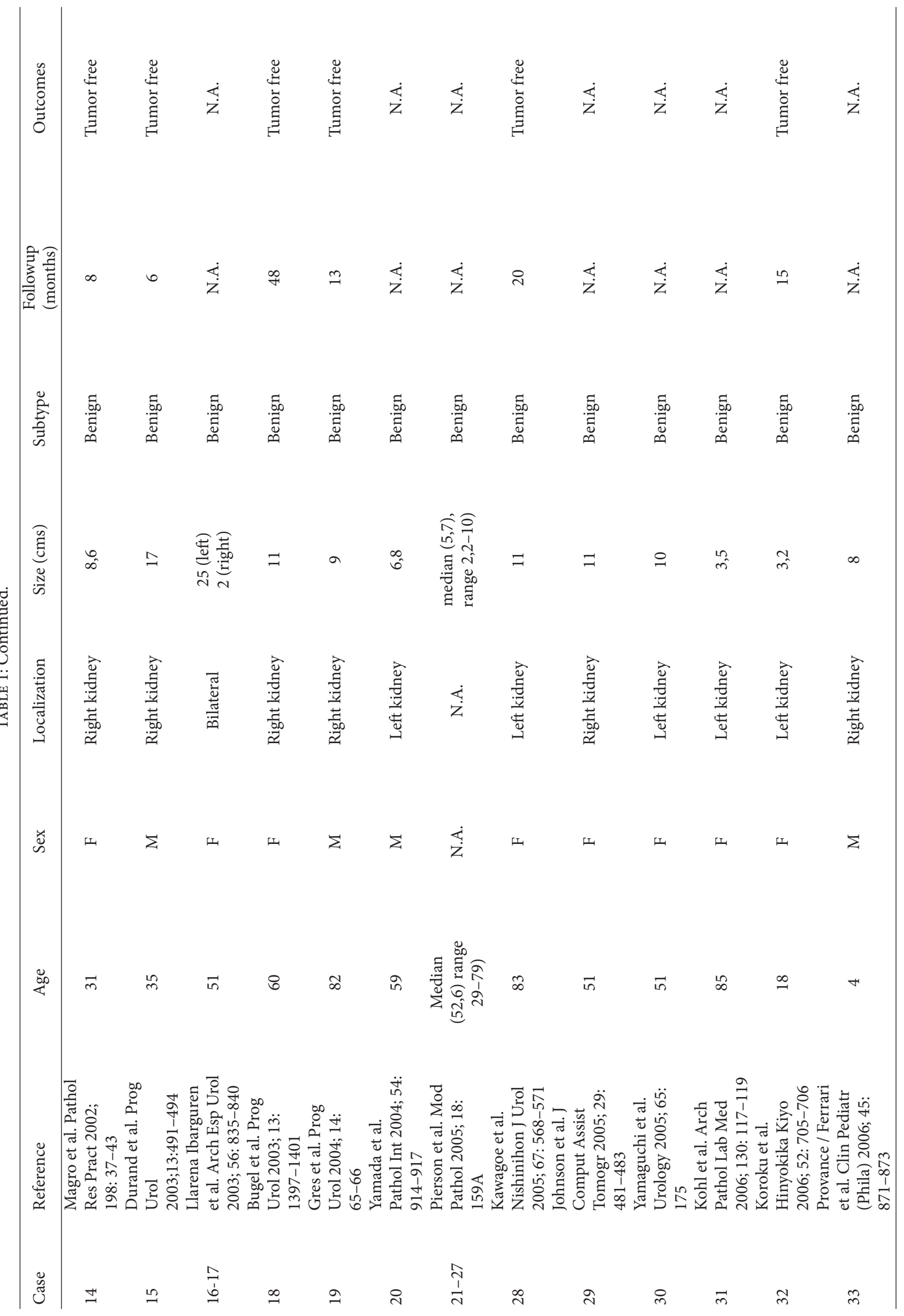




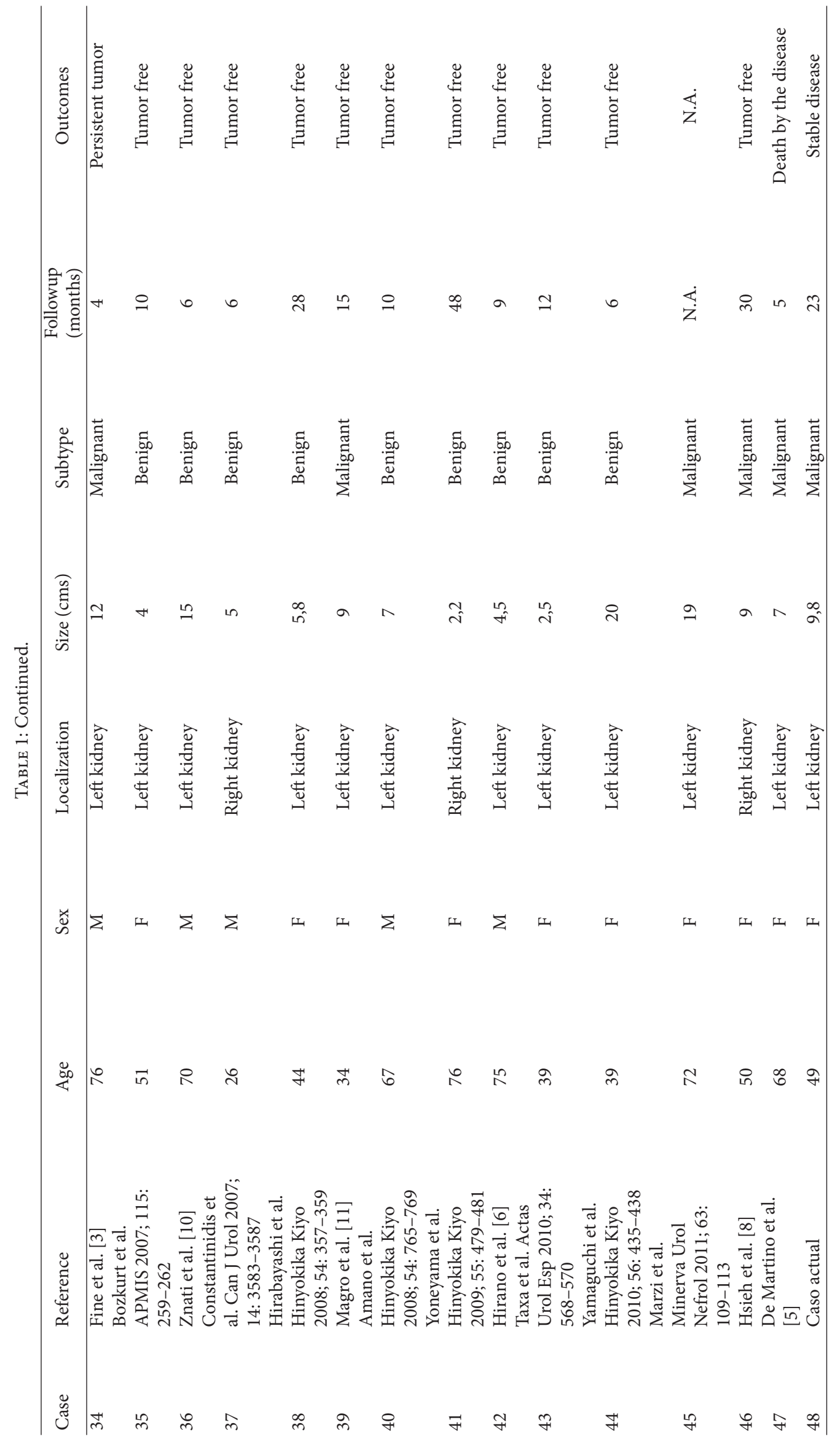


TABLE 2: Clinicopathologic features and outcomes of the 49 cases reported with solitary fibrous tumors of the kidney.

\begin{tabular}{|c|c|}
\hline Median age in years (range) & $51(4-85)$ \\
\hline \multicolumn{2}{|l|}{ Sex } \\
\hline Male & 14 \\
\hline Female & 28 \\
\hline Unknown & 7 \\
\hline \multicolumn{2}{|l|}{ Location } \\
\hline Left kidney & 23 \\
\hline Right kidney & 17 \\
\hline Bilateral & 1 \\
\hline Unknown & 8 \\
\hline \multicolumn{2}{|l|}{ Site } \\
\hline Kidney & 33 \\
\hline Renal capsule & 6 \\
\hline Peripelvis & 3 \\
\hline Pelvis & 1 \\
\hline Unknown & 6 \\
\hline Medium size in $\mathrm{cm}$ (range) & $7,6(2-20)$ \\
\hline \multicolumn{2}{|l|}{ Histology } \\
\hline Benign & 42 \\
\hline Malignant & 7 \\
\hline \multicolumn{2}{|l|}{ Treatment } \\
\hline Tumor resection & 2 \\
\hline Nephrectomy & 41 \\
\hline Unknown & 6 \\
\hline Subcutaneous interferon & 1 \\
\hline \multicolumn{2}{|l|}{ Outcome } \\
\hline No evidence of disease & 25 \\
\hline Metastasis & 4 \\
\hline Unknown & 20 \\
\hline
\end{tabular}

\section{References}

[1] J. K. Chan, "Solitary fibrous tumour-everywhere, and a diagnosis in vogue," Histopathology, vol. 31, no. 6, pp. 568-576, 1997.

[2] T. Hasegawa, Y. Matsuno, T. Shimoda, F. Hasegawa, T. Sano, and S. Hirohashi, "Extrathoracic solitary fibrous tumors: their histological variability and potentially aggressive behavior," Human Pathology, vol. 30, no. 12, pp. 1464-1473, 1999.

[3] J. S. Fain, J. Eble, A. G. Nascimento, G. M. Farrow, and D. G. Bostwick, "Solitary fibrous tumor of the kidney: report of three cases," Journal of Urology, vol. 4, pp. 227-238, 1996.

[4] A. B. Gelb, M. L. Simmons, and N. Weidner, "Solitary fibrous tumor involving the renal capsule," American Journal of Surgical Pathology, vol. 20, no. 10, pp. 1288-1295, 1996.

[5] M. Fukunaga and T. Nikaido, "Solitary fibrous tumour of the renal peripelvis,” Histopathology, vol. 30, no. 5, pp. 451-456, 1997.

[6] T. Hasegawa, Y. Matsuno, T. Shimoda, F. Hasegawa, T. Sano, and S. Hirohashi, "Extrathoracic solitary fibrous tumors: their histological variability and potentially aggressive behavior," Human Pathology, vol. 30, no. 12, pp. 1464-1473, 1999.

[7] X. Leroy, M. C. Copin, J. M. Coindre et al., "Solitary fibrous tumour of the kidney," Urologia Internationalis, vol. 65, no. 1, pp. 49-52, 2000.
[8] S. W. Fine, D. M. McCarthy, T. Y. Chan, J. I. Epstein, and P. Argani, "Malignant solitary fibrous tumor of the kidney: report of a case and comprehensive review of the literature," Archives of Pathology and Laboratory Medicine, vol. 130, no. 6, pp. 857-861, 2006.

[9] L. F. J. Guillou, C. D. M. Fletcher, and N. Mandahi, "Extrapleural solitary fibrous tumour and hemangiopericytoma," in World Health Organization Classification of Tumours: Pathology and Genetics of Tumours of Soft Tissue and Bone, C. D. M. Fletcher, K. K. Unni, and F. Mertens, Eds., pp. 86-90, IARCPress, Lyon, France, 2002.

[10] D. Hirano, A. Mashiko, Y. Murata et al., "A case of solitary fibrous tumor of the kidney: an immunohistochemical and ultrastructural study with a review of the literature," Medical Molecular Morphology, vol. 42, no. 4, pp. 239-244, 2009.

[11] M. De Martino, M. Böhm, and T. Klatte, "Malignant solitary fibrous tumour of the kidney: report of a case and cumulative analysis of the literature," Aktuelle Urologie, vol. 43, no. 1, pp. 59-62, 2012.

[12] M. Pandey, K. C. Kothari, and D. D. Patel, "Haemangiopericytoma: current status, diagnosis and management," European Journal of Surgical Oncology, vol. 23, no. 4, pp. 282-285, 1997.

[13] H. N. Naveen, G. N. Nelivigi, G. K. Venkatesh, and V. Suriraju, "A case of solitary fibrous tumor of the kidney," Urology Annals, vol. 3, no. 3, pp. 158-160, 2011.

[14] T. Y. Hsieh, Y. C. ChangChien, W. H. Chen et al., "De novo malignant solitary fibrous tumor of the kidney," Diagnostic Pathology, vol. 6, article 96, 2011.

[15] S. B. Park, Y. S. Park, J. K. Kim et al., "Solitary fibrous tumor of the genitourinary tract," American Journal of Roentgenology, vol. 196, no. 2, pp. W132-W137, 2011.

[16] G. Magro, C. Emmanuele, M. Lopes, G. Vallone, and P. Greco, "Solitary fibrous tumour of the kidney with sarcomatous overgrowth," APMIS, vol. 116, no. 11, pp. 1020-1025, 2008.

[17] K. Znati, L. Chbani, H. El Fatemi et al., "Solitary fibrous tumor of the kidney: a case report and review of the literature," Reviews in Urology, vol. 9, no. 1, pp. 36-40, 2007.

[18] T. Yokoi, T. Tsuzuki, Y. Yatabe et al., "Solitary fibrous tumour: significance of $\mathrm{p} 53$ and CD34 immunoreactivity in its malignant transformation," Histopathology, vol. 32, no. 5, pp. 423-432, 1998.

[19] M. S. Park and D. M. Araujo, "New insights into the hemangiopericytoma/solitary fibrous tumor spectrum of tumors," Current Opinion in Oncology, vol. 21, no. 4, pp. 327-331, 2009.

[20] M. S. Park, S. R. Patel, J. A. Ludwig et al., "Activity of temozolomide and bevacizumab in the treatment of locally advanced, recurrent, and metastatic hemangiopericytoma and malignant solitary fibrous tumor," Cancer, vol. 117, no. 21, pp. 4939-4947, 2011. 


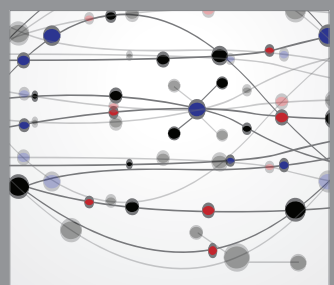

The Scientific World Journal
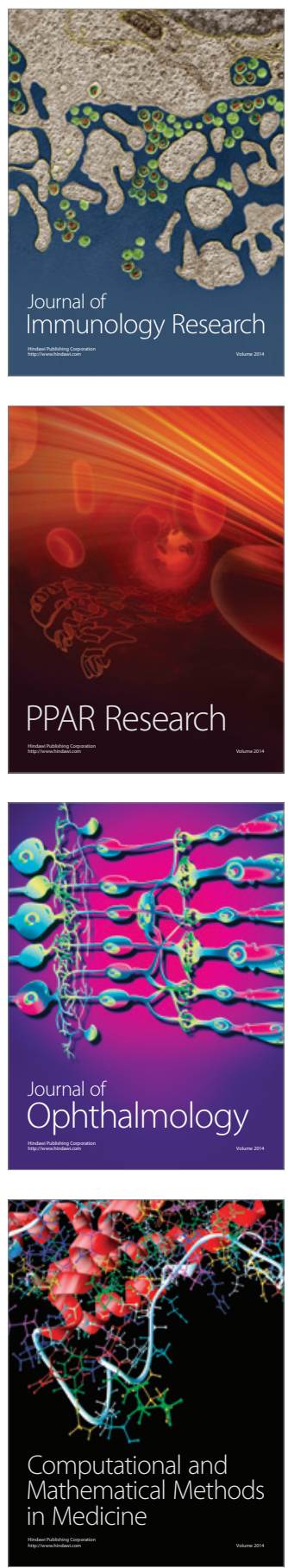

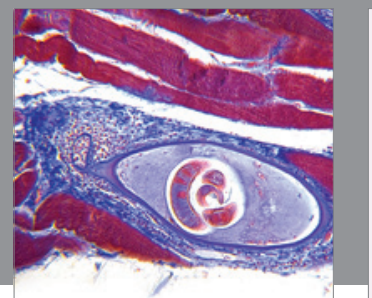

Gastroenterology

Research and Practice
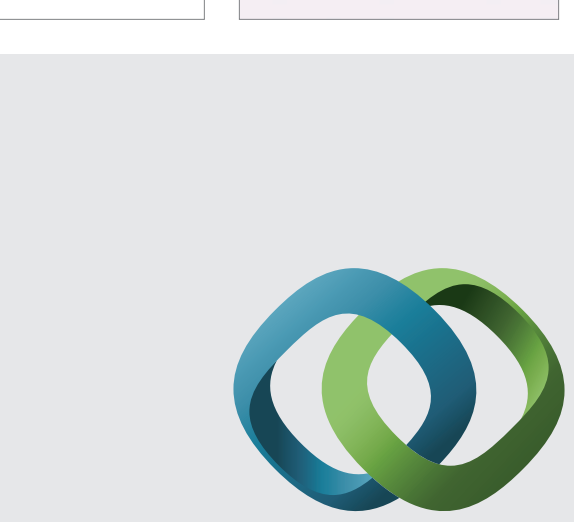

\section{Hindawi}

Submit your manuscripts at

http://www.hindawi.com
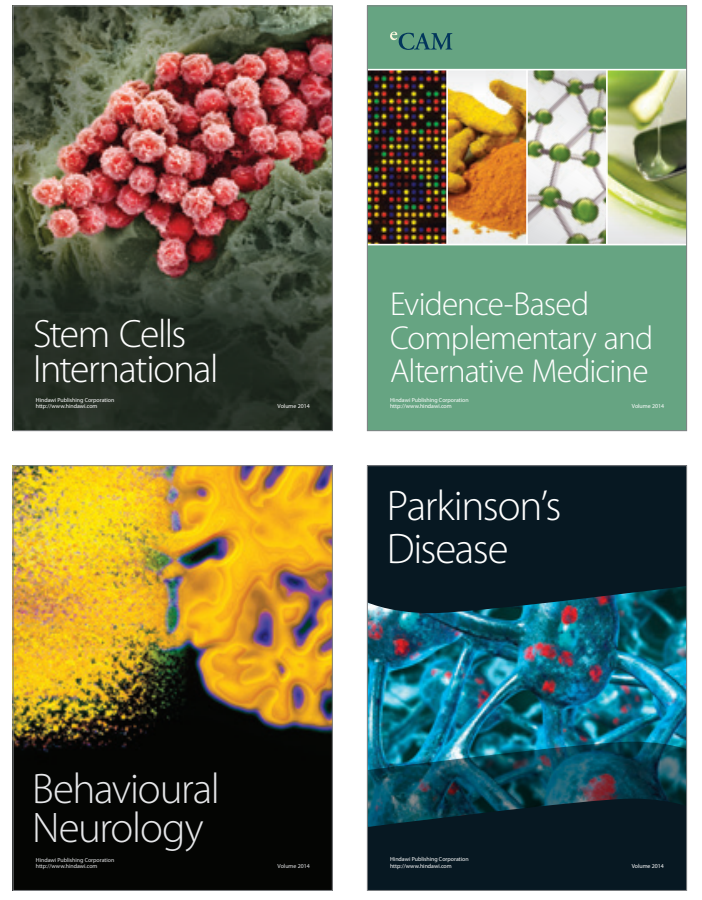
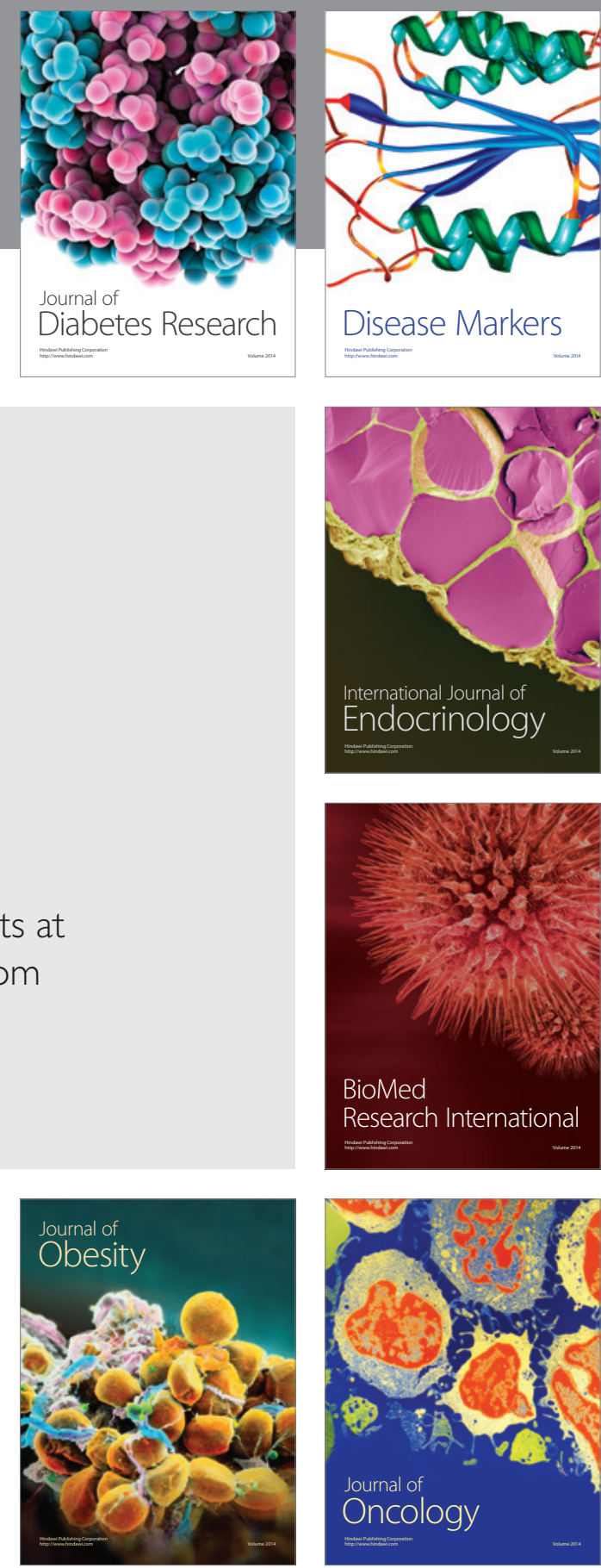

Disease Markers
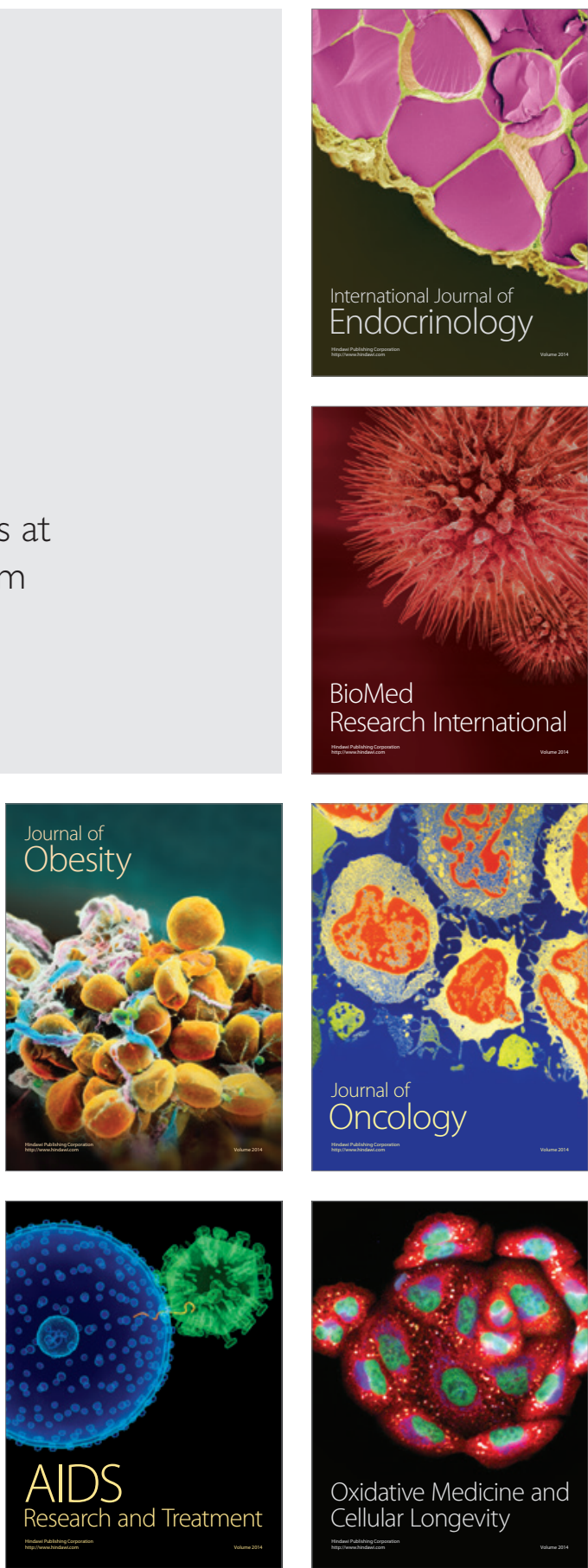